\title{
Production of Oyster Mushroom (Pleurotus ostreatus) on Substrate Composed from Wheat Straw, Waste Paper and Cotton Seed Waste
}

\author{
Abera Getachew $^{1}$, Asefa Keneni ${ }^{2}$, Mosisa Chawaka ${ }^{3}$ \\ ${ }^{1}$ Department of Horticulture, Wollega University, Nekemt, Ethiopia \\ ${ }^{2}$ Department of Biology, Ambo University, Ambo, Ethiopia \\ ${ }^{3}$ Department of Horticulture, Ambo University, Ambo, Ethiopia \\ Email address: \\ ebaabera21@gmail.com (A. Getachew),asefa_keneni@yahoo.com(A. Keneni), agamosisa@gmail.com (M. Chawaka) \\ To cite this article: \\ Abera Getachew, Asefa Keneni, Mosisa Chawaka. Production of Oyster Mushroom (Pleurotus ostreatus) on Substrate Composed from \\ Wheat Straw, Waste Paper and Cotton Seed Waste. International Journal of Microbiology and Biotechnology. Vol. 4, No. 2, 2019 , pp. 38-44. \\ doi: $10.11648 /$ j.ijmb.20190402.12
}

Received: April 17, 2019; Accepted: May 31, 2019; Published: June 26, 2019

\begin{abstract}
Due to the recent insights of the mushroom nutritional and medicinal advantages, interests in mushroom production and consumption have been increasing. The main aim of this paper is to report the effect of substrates' composed from different mix ratio of wheat straws, waste paper and cotton seed waste on growth, yield and yield related parameters of oyster (Pleurotus ostreatus) mushroom. The experiment was conducted from December 20017 to March 2018. There were five treatments (T1-T5) with two replications in randomized complete design. The quantitative data were collected and analyzed. The results of this experiments indicated that, the fastest mycelia run was recorded from T4 (19.5 days) for complete colonization and the slowest from T1 (28 days) for complete colonization. Fewer days from colonization to primordial formation was taken for treatment T3 and T4 (2.5 days), while more days taken for T5 (4 days. Larger cap diameter (11.19 cm) was recorded for the mushroom grown on T1. While smaller cap diameter 96.23) was recorded for the mushroom grown on $\mathrm{T} 4$, shortest stipe length was recorded from the mushroom on T5 while longest stipe length was recorded for T2, (4.11); highest number of fruits recorded for T3 (41.44) while lowest number of fruits recorded for T5 (22.07). Highest number of aborts recorded for T2 (18.78, while the lowest was recorded for T5 (10.37); Highest number of bunches recorded for T4, (4) while the lowest number of bunches recorded for T5 (1.38). Maximum number of fruits 41.44 (T3), highest biological efficiencies 191.745 (T5), were produced from the different substrate composed from wheat straw, waste paper supplemented with cotton seed waste. Treatments T3 and T4 of this experiment gave maximum total biomass and Biological efficiency so that it could be recommended for pilot or large scale production of oyster mushroom.
\end{abstract}

Keywords: Biological Efficiency, Cotton Seed Waste, Waste Paper, Wheat Straw, Yield

\section{Introduction}

The word mushroom is derived from the Gallo Roman mussiro [1] which is defined as a "macro-fungus" that has a fleshy and used throughout the world to describe the fruiting bodies of saprophytic, mycorrhizal and parasitic fungi belong to the order of Basidomyecets [2]. According to [3] a mushroom is a fungus that has different body structure like a stem, a cap and gills or pores on the underside of its cap. Mushrooms are not only basidiomycetes, they can also be Ascomycetes that can grow underground and have a non- fleshy texture and could be inedible [4]. Mushrooms are found in soils rich in organic matter and humus, moist wood, animals waste after heavy rain or a sudden change of temperature and soon after a few hours or day's they disappear, leaving no sign but, mycelium [2]. As a the report of [5] by estimation 14,000 of mushrooms species are expressed from 1.5 million fungi [6] found in the world produce fruiting bodies that are so large to be considered as mushrooms and [7] it has been estimated that over 70,000 species of fungi are found and of which about 2000 species (31 genera) are regarded as prime edible mushrooms. 
However, the numbers of poisonous mushrooms are relatively small, approximately only about $10 \%$ and 30 of species are considered to be lethal [8]. There are high diversity of wild mushroom in Africa [9] but society have no enough information about wild edible mushroom in many countries of the African continent. According to the report [10]there is no reports about wild edible mushroom in many African countries and he has also showed that there are better reports considering wild edible mushrooms in some African countries like, Cameroon, Morocco, Kenya, South Africa, Zambia, Zimbabwe, Nigeria and Democratic Republic of Congo. Mushroom cultivation is a relatively new technology and the mushroom industry is still small compared to many plant crops. In addition, the investment on mushroom production in Ethiopia is low. Primarily, mushroom cultivation in Ethiopia started as small scale by cultivation of the oyster (Pleurotus ostreatus) in 1997. Then after, Agarics bisporus followed by the shiitake (Lentinula edodes) mushrooms were introduced for commercial purpose [9]. Small scale mushroom production is an essential opportunity for farmers who have interest to do as an additional work, and is good opportunity for farmers who have no enough farm lands [11]. In general, the major constituent of mushrooms is water $90 \%$ and the rest $10 \%$ (dry or wet basis) is protein, fat, carbohydrates, fiber and ash [12]. Pleurotus ostreatus (oyster mushroom) is primarily consumed for its nutritive value and is used industrially as a bioremediation. The genus Pleurotus (oyster mushroom) comprises some most popular edible mushrooms due to their favourable organoleptic [13]. Pleurotus species possess many medicinal characteristics, such as immune-modulatory, hypocholesterolaemic, antihypertensive antigen-toxic, antioxidant, anti-inflammatory, anti-tumour, antiplateletaggregating, anti-hyper glycemic, antimicrobial and antiviral activities [14].

These therapeutic activities are manifested by extracting compounds from Pleurotus spp. fermentation broth, mycelia and fruiting bodies specifically polysaccharides are the most effective extracts of oyster mushroom [15]. Mushrooms play a vital role in human life due to various benefits. The mushroom cultivation practices can raise the economy of country and can enhance food security with sustainable use of natural resources. Cultivation of oyster mushrooms has recently become common practise throughout the world, because of their abilities to grow at a wide range of temperatures utilizing various lingo cellulosic substrates [16]. Cultivation of oyster mushrooms ( $P$. ostreatus) based on the chemical composition of major substrates and additional supplement employed in mixture or compost form by different method [17] reported that in Ethiopia there are about 22 companies that involved in paper making and trading businesses. Ethiopian uses imported pulp for their paper mills while others import and produce paper rolls for further processing [17]. Ethiopia has been imported 7.8 million tons of pulp at a cost of 6.3 million USD and 151 million tons of paper at a cost of 167 million USD in 2016 [18]. Only about 5\% of the country's paper demand is produced in the country and the rest will be covered by importing finished paper from abroad and those paper which is left as waste after used suitable for production of mushrooms rather than accumulating in the environment and causes for pollution. In this regards the production of oyster mushroom from wheat straws, waste paper and cotton seed wastes and nutritional qualities of the produced mushrooms were not properly studied and addressed. So, the present studies was under taken in order to assess the usability of wheat straw alone or together with the waste papers with the supplement of different proportion of cotton seed waste for the production of oyster mushroom (Pluerotus strautus).

\section{Materials and Methods}

\subsection{Description of the Study Area}

The study was conducted in Oromia regional state, West Shoa at Ambo town in Ambo University. Ambo is located $110 \mathrm{Km}$ to West of the capital Addis Ababa, on the road to Nekemt. The Latitude and Longitude of Ambo University is $8.9^{0}$ and $37.8^{0}$ respectively.

\subsection{Organism and Culture Conditions}

The fungal strain, Pleurotus ostreatus (Oyster mushroom) was obtained from the Mycology Laboratory, Department of Biology Addis Ababa University, Ethiopia. The pure culture of Pleurotus ostreatus was transferred to Potato Dextrose Agar (PDA) prepared in the laboratory, Department of Biology using fresh potato $250 \mathrm{~g}$, glucose (Dextrose) $20 \mathrm{~g}$, agar $20 \mathrm{~g}$ and chloramphenicol $0.2 \mathrm{~g}$ in $1000 \mathrm{ml}$ of water.

The medium was poured into the Petri-dishes and allowed to cool under aseptic condition in a laminar flow chamber. The cooled and solidified medium was inoculated with $1 \mathrm{~cm} \mathrm{x}$ $1 \mathrm{~cm}$ agar block of the fungal strain and incubated at $28^{\circ} \mathrm{C}$. The growth of the culture and presence of contamination were visually inspected at three day intervals [9].

\subsection{Grain Spawn Productions}

In this study, the spawn (mushroom seed) of Pleurotus ostreatus was produced on yellow colored sorghum grain (Sorghum bicolor L), wheat bran and calcium sulfate (gypsum) in the ratio of $88: 10: 2$ respectively [9]. The required amount of sorghum grain was weighed and soaked overnight in a sufficient amount of water. The grains were washed and drained to remove the dead and floating seeds with water. After removing the excess water from the grain, the required amount of wheat bran and gypsum $\left(\mathrm{CaSO}_{4} \cdot 2 \mathrm{H}_{2} \mathrm{O}\right)$ were added and transferred to $1000 \mathrm{ml}$ glass bottles ( $75 \%$ level) leaving a head space over the grain and autoclaved at $121^{\circ} \mathrm{C}$ temperature for 45 minutes. After cooling, each bottle was inoculated with 20 agar blocks (1 $\mathrm{cm} \times 1 \mathrm{~cm}$ ) of a 15day old mushroom culture from the Petri dish and incubated for 21 days at $28^{\circ} \mathrm{C}$ until the substrate were fully colonized and the mycelia invasion and contamination were inspected at five day intervals and after 15 days the grain spawn was ready to use [19]. 


\subsection{Substrate Collection and Preparation}

Wheat straw and cotton seed wastes were collected from and around Ambo town rural kebeles and from Addis Ababa, respectively. Lime stone and wheat bran were obtained from Laboratory of Biology department, Ambo University. The wheat straws were cut into small pieces approximately $(3-5 \mathrm{~cm})$ weighed and soaked in a sufficient amount of water over night in order that it absorb sufficient amount of water. Cotton seed wastes were weighed and soaked in sufficient amount of water over night [20]. After excess water in the substrates was drained, the substrates were mixed with $10 \%$ wheat bran, one percent calcium carbonate, and then filled in yellow colored polyethylene bags $(75 \mathrm{~cm}$ length and $65 \mathrm{~cm}$ width) in order to sterilize the substrates. The substrate prepared were autoclaved at15Psi pressure and at $121^{\circ} \mathrm{C}$ temperatures for $1 \mathrm{~h}$ [19].

\subsection{Spawning and Spawn Running}

After sterilization, the substrates were transferred to transparent polyethylene cultivation bags $(65 \mathrm{~cm}$ length and $45 \mathrm{~cm}$ width) for easy supervision of the growth of the mycelia and presence of contamination. After cooling under normal temperature, each substrate $(500 \mathrm{~g})$ with $70 \%$ moisture was mixed with $10 \%$ spawn (dry weight/wet weight basis) under laminar flow hood and the inoculated polythene bags were then tightly tied with string made from cotton cloth. Pin holes were made by sterilized needle through bags $\left(1 / 100 \mathrm{~cm}^{2}\right)$ or $(10-14)$ per bag for drainages and aerations [19]. Then the inoculated bags were kept in a spawn running room at room temperature $\left(23-25^{\circ} \mathrm{C}\right)$ in the dark until primordial were formed.

\subsection{Fruiting, Watering and Harvesting}

After primordial formation, the bags were transferred to mushroom production house and large holes were made, through the polythene bags to allow normal development of fruiting bodies. The bags were arranged in simple randomization in zigzag forms at 15 to $20 \mathrm{~cm}$ apart from each other [19]. In the mushroom house, the bags were kept under normal environmental conditions and relative humidity of the room was maintained at $85-90 \%$ by keeping water in open containers at different corners of the room [19]. The bags were irrigated using tap water every morning and evening until all flushes of Pleurotus ostreatus fruiting bodies were harvested. Adequate ventilation was provided to prevent increased $\mathrm{CO}_{2}$ concentration in the room by opening the door and windows of the room for half an hour in the morning and in the evening and also in the mid-day when temperature of cropping house was increased [19].

The fruiting bodies were harvested manually by twisting to clock wise or anti-clock wise direction by hand without lifting stubs on the substrates at one time for uniform harvesting to the next flush.

\subsection{Experimental Design}

The experiment was set up in a Completely Randomized Design (CRD) with two replications in 5 levels of waste paper and wheat straw supplemented with cotton seed wastes substrate. The control treatment was waste paper plus wheat straw $(50 \%$ and $50 \%)$ as referring [21] waste paper and wheat bran. The mixing levels proportions for the substrates of waste paper and wheat straws supplemented with cotton seed wastes are presented in Table 1 blow.

Table 1. The different mix ratio of wheat straws, waste paper and cotton seed waste treatments.

\begin{tabular}{lllllllll}
\hline TTMTS & WS g & WS\% & WP g & WP\% & CW g & CW\% & TS & Remark \\
\hline (T1) & 250 & 50 & 250 & 50 & - & - & 500 & Control \\
(T2) & 200 & 40 & 200 & 40 & 100 & 20 & 500 & \\
(T3) & 150 & 30 & 150 & 30 & 200 & 40 & 500 & \\
(T4) & 125 & 25 & 125 & 25 & 250 & 50 & 500 & \\
(T5) & 100 & 20 & 100 & 20 & 300 & 60 & 500 & \\
\hline
\end{tabular}

TRTMS = treatments, WS in $\mathrm{g}=$ wheat straws in gram, WP = waste paper in gram, CSW in $\mathrm{g}=$ cotton seed waste, $\mathrm{TS}$ in $\mathrm{g}=$ total substrates in gram.

\subsection{Biological Efficiency}

Total weight of the fruiting bodies harvested from the substrates within first to fourth flush was measured as total yield of the mushroom. The biological efficiency (yield of mushroom per $\mathrm{kg}$ substrate on dry weight basis) was calculated as the formula proposed by Chang et al. (1993).

$$
\mathrm{BE}(\%)=(\mathrm{FWM} / \mathrm{DWS}) \times 100
$$

$\mathrm{BE}=$ Biological Efficiencies, $\mathrm{FWM}=$ Fresh weight of mushroom and DWS=Dry weight of substrates

\subsection{Data Collection and Analysis}

The number of days for full colonization of the substrates, day taken for primordial formation after colonization; time taken from Primordial emergence, to mature fruit body formation, was recorded. Cap diameter of mature, stipe length, number of fruits, number of aborts, number of bunches were recorded for each treatments in each cycle of harvest collected and recorded. Fresh weight of mushroom in each cycle of harvest and total biomass and biological efficiency were recorded.

\subsection{Data Analysis}

The collected data on proximal compositions were subjected to Analysis of Variance (ANOVA) [22]with two replications using Statistical Analysis System (SAS Institute and Cary NC) Version 9.0. Means were compared for significant difference using Fisher's LSD (FLSD) at $\mathrm{P}<0.05$.

\section{Results and Discussion}

\subsection{Vegetative Growth of Oyster Mushroom on the Different Substrate Mix}

The days taken for full mycelia colonization for the different substrates composed from wheat straws and waste paper supplemented with cotton seed waste had significant ( $\mathrm{P}$ $<0.05$ ) differences within the treatments (Table 2). T4 took fastest days to fully colonize the substrate was 19.5 days and T1 took longest days 28 days to fully colonize the substrates. 
The lengths of the days for remaining treatments were intermediate between the shortest and the longest. The length of day taken to fully colonize the substrates for this study was in line with the results reported by [23] the full colonization of substrates (rice straws + wheat straws and rice with paper) by oyster mushroom was taken 22.4 days to 26 days.

The effects of different mixing ratio of wheat straws and waste paper supplemented with cotton seed waste on days of primordial formation of oyster mushroom had significant $(p<0.05)$ differences within the treatments (Table 2). However, for wheat straws and waste paper supplemented with cotton seed waste the longest days (4) taken for primordial formation was on T5, and shortest days (2.5) were taken from T3 and T4. The length of days taken for primordial initiation for this experiment was in line with the length of days reported by [23] for substrates of wheat straws, paper and rice straws taken 4days to 5.6days (22.60-26 days to 26.40-31.60) from mycelium fully colonize to primordial formation. The effects of wheat straws and waste paper supplemented with cotton seed waste on days of oyster mushroom first harvest had significant $(p<0.05)$ differences within the treatments (Table 2).

The shortest days from primordial formation to the first harvest was observed form treatment T4, was 3.25 days while, T2 took longer days from primordial formation to first harvest 6 days. The remaining treatments were took intermediate days between the shortest and the longest days from primordial formation to the first harvest. The results of this experiment were related to the days of first harvest from primordial initiation (3.6 to 6.5) reported [23] for the substrates composed from wheat straws, rice and waste papers.

As [24] was reported in his investigation, the days taken to phonological growth of the oyster mushroom grown on different mixing amounts of growth substrates, the interim period of pin-head formation varied with substrates, ranging from 17 to 33 days after spawn seeding and also Pin-head formation occurred quickly in cotton seed (17 days), followed by sawdust (29 days); while it took relatively longer time in wheat straw (32.66 days).

Table 2. Effects of substrates composed from different mix ratio of wheat straws, waste paper and cotton seed waste on growth days of oyster mushroom from spawning to first flush harvesting.

\begin{tabular}{llll}
\hline \multicolumn{4}{l}{ Length of days } \\
\hline Treatments & DMFCS & DPEAMFCS & DMAPE \\
\hline T1 & $28.00^{\mathrm{a}}$ & $3.00^{\mathrm{ab}}$ & $4.75^{\mathrm{b}}$ \\
$\mathrm{T} 2$ & $21.50^{\mathrm{bc}}$ & $3.40^{\mathrm{ab}}$ & $6.00^{\mathrm{a}}$ \\
$\mathrm{T} 3$ & $20.00^{\mathrm{c}}$ & $2.50^{\mathrm{b}}$ & $4.75^{\mathrm{b}}$ \\
$\mathrm{T} 4$ & $19.50^{\mathrm{c}}$ & $2.50^{\mathrm{b}}$ & $3.25^{\mathrm{c}}$ \\
T5 & $25.50^{\mathrm{ab}}$ & $4.00^{\mathrm{a}}$ & $4.75^{\mathrm{b}}$ \\
Mean & 22.9 & 3.08 & 3.2 \\
CV & 6.4 & 11.88 & 6.73 \\
LSD (5\%) & 1.38 & 1.01 & 0.88 \\
Sign. & $\mathrm{ns}$ & $*$ & $*$ \\
\hline
\end{tabular}

$\mathrm{LSD}=$ least significant differences, $\mathrm{CV}=$ coefficient variances, $\mathrm{M}=$ Mean, DMFCS = day of mycelia fully colonize substrates, DPEAMFC $=$ days of primordial after mycelia fully colonized substrates, DMAPE = days of maturation after primordial emergences,

Mean values with in a column sharing the same superscript letters are not significantly different by using LSD test at $\mathrm{P} \leq 0.05$.

\subsection{Cap-Diameters and Stipe Length of Oyster Mushrooms}

The effects of different mixing amounts of wheat straws, waste paper supplemented with cotton seed wastes on capdiameters and stipe length of oyster mushroom had significant $(\mathrm{p}<0.05)$ differences (Table 3$)$. In this study the larger cap-diameters and stipe length of oyster mushroom grown on these substrates were $11.19 \mathrm{~cm}$ and $4.11 \mathrm{~cm}$, respectively which were recorded on the bags of T3 and T2. But, the smallest cap-diameter was $6.23 \mathrm{~cm}$ which was measured from T4 and the shortest stipe length was measured from $\mathrm{T} 5$ and $\mathrm{T} 3$, were $2.02 \mathrm{~cm}$ and $2.11 \mathrm{~cm}$, respectively. The rest of the treatments were intermediate between the longest and shortest of these parameters.

The longest and shortest means of cap-diameters and stipe length in this study was related to the results reported by [25] in his study under substrates of wheat straws and cotton wastes $4.50 \mathrm{~cm}$ to $17.12 \mathrm{~cm}$ for cap-diameters and $2.50 \mathrm{~cm}$ to $5.24 \mathrm{~cm}$ for stipe length. But, the results of this parameters in other hand were disagree with the results reported by [23] from substrates composed of wheat straws, paper and rice $6.11 \mathrm{~cm}-7.4 \mathrm{~cm}$ and $2.25 \mathrm{~cm}-3.08 \mathrm{~cm}$, this differences may be due to the nutritional contents of substrates as [26] reported in his studies the longest and wider stipe and cap-diameters of mushrooms were depend on the substrates on which the mushroom can be cultivated.

Table 3. Effects of different mixing amounts of wheat straws and waste paper supplemented with cotton seed waste on growth parameters of oyster mushroom.

\begin{tabular}{lll}
\hline \multirow{2}{*}{ Treatments } & \multicolumn{2}{l}{ Mean separation of growth parameters } \\
\cline { 2 - 3 } & CD & SL \\
\hline T1 & $9.38^{\mathrm{b}}$ & $3.18^{\mathrm{b}}$ \\
T2 & $8.11^{\mathrm{c}}$ & $4.11^{\mathrm{a}}$ \\
T3 & $11.19^{\mathrm{a}}$ & $2.11^{\mathrm{c}}$ \\
T4 & $6.23^{\mathrm{d}}$ & $3.22^{\mathrm{b}}$ \\
T5 & $8.45^{\mathrm{c}}$ & $2.02^{\mathrm{c}}$ \\
Mean & 8.67 & 2.92 \\
LSD (5\%) & 0.92 & 0.52 \\
CV & 3.81 & 6.42 \\
Sign. & $*$ & $*$ \\
\hline
\end{tabular}

Mean values with in a column sharing the same superscript letter(s) are not significantly different by using $\mathrm{LSD}$ test at $\mathrm{P} \leq 0.05, \mathrm{CD}=$ cap-diameter, $\mathrm{SL}=$ stipe length, $\mathrm{CV}=$ coefficient variances, $\mathrm{LSD}=$ least significant differences at $\mathrm{p}=0.05$

\subsection{Number of Fruits, Aborts and Bunches of Oyster Mushroom}

The effects of wheat straw, waste paper supplemented with cotton seed waste on numbers of fruits, aborts and bunches had significant $(p<0.05)$ differences within the treatments (Table 4). The maximum number of fruits (41.44) were recorded from treatment $\mathrm{T} 3$, the maximum number of aborts (18.78) were recorded from the treatment $\mathrm{T} 2$ and the maximum number of bunches (4) from treatment T4, while, the minimum number of these parameters vs., fruit body (16.94) from T8, abort (8) from T1 and bunches (1.25) from $\mathrm{T} 1$, while all the remaining treatments showed intermediate between the maximum and minimum for this parameters, and 
the minimum numbers of fruits, aborts and bunches were 22.07, 10.37 and 1.38 which were recorded from T5, for all parameters respectively. The result of this study was significantly lower when compared to the results reported by [21] in investigated number of aborts, fruits and bunches of oyster mushroom grown on waste paper supplemented with wheat bran were $16-110,22-72$ and $3-5$, respectively.

Table 4. Effects of substrates composed from different mix ratio of wheat straws, waste paper and cotton seed waste on number of fruiting, aborting and bunching of oyster mushroom.

\begin{tabular}{llll}
\hline \multirow{2}{*}{ Treatments } & \multicolumn{3}{l}{ Growth parameters } \\
\cline { 2 - 4 } & NF & NA & NB \\
\hline T1 & $36.50^{\mathrm{b}}$ & $11.37^{\mathrm{dc}}$ & $2.00^{\mathrm{c}}$ \\
$\mathrm{T} 2$ & $30.63^{\mathrm{c}}$ & $18.78^{\mathrm{a}}$ & $3.00^{\mathrm{b}}$ \\
$\mathrm{T} 3$ & $41.44^{\mathrm{a}}$ & $12.22^{\mathrm{c}}$ & $2.12^{\mathrm{c}}$ \\
T4 & $27.44^{\mathrm{d}}$ & $14.36^{\mathrm{b}}$ & $4.00^{\mathrm{a}}$ \\
T5 & $22.07^{\mathrm{e}}$ & $10.37^{\mathrm{d}}$ & $1.38^{\mathrm{d}}$ \\
Mean & 31.61 & 13.42 & 2.5 \\
CV\% & 2.30 & 2.73 & 4.02 \\
LSD (5\%) & 2.02 & 1.02 & 0.27 \\
Sign. & $* *$ & $* *$ & $* *$ \\
\hline
\end{tabular}

Mean values with in a column sharing the same superscript letter(s) are not significantly different by using LSD test at $\mathrm{P} \leq 0.05$

$\mathrm{NF}=$ number of fruiting, $\mathrm{NA}=$ number of aborting, $\mathrm{NB}=$ number of bunching, $\mathrm{CV}=$ coefficient variances, $\mathrm{LSD}=$ least significant differences at $\mathrm{p}=0.05$

\subsection{Fresh Weight of Oyster Mushroom}

The mean fresh weight of oyster mushroom from $1^{\text {st }}$ flush to the $4^{\text {th }}$ flush harvested from substrate composed from wheat straws and waste paper supplemented with cotton seed wastes were indicated in (Table 5). The fresh weight of oyster mushroom grown on wheat straws and waste paper supplemented with cotton seed waste in $1^{\text {st }}, 3^{\text {rd }}$ and $4^{\text {th }}$ flush had highly significant $(p<0.05)$ differences within the treatments but, the $2^{\text {nd }}$ flush fresh weight of oyster mushroom did not showed significant $(\mathrm{p}>0.05)$ differences within the treatments (Table 5). The maximum and minimum fresh weight of oyster mushroom under the $1^{\text {st }}$ flush was $448.5 \mathrm{~g}$ and $357 \mathrm{~g}$ which were collected from T5 and T1 respectively, however the largest and the smallest fresh weight of oyster mushroom picked at the $2^{\text {nd }}$ flush was $268.5 \mathrm{~g}$ and $178.5 \mathrm{~g}$ which were collected from T3 and T1, respectively. In the $3^{\text {rd }}$ flush, the maximum and minimum fresh weight of oyster mushroom was $184 \mathrm{~g}$ and $80.5 \mathrm{~g}$ which were harvested from $\mathrm{T} 2$ and T5 respectively. And also the maximum and minimum fresh weight of oyster mushroom picked in the $4^{\text {th }}$ flush was $153 \mathrm{~g}$ and $71.5 \mathrm{~g}$ which were collected from T1 and T5 respectively. The results of this study were related to the means of fresh weight reported by [21]. [27] Reported that yields of mushroom in different substrates slightly declined from the first flush to the successive harvests. The crops of oyster mushroom were harvested in four flushes and the maximum yield was obtained in the first flush than the 2nd, 3rd and 4th flushes and also the results of this study was related to the means of fresh weight reported by [21] ranges from $553 \mathrm{~g} / 500 \mathrm{~g}$ to $522.5 \mathrm{~g} / 500 \mathrm{~g}(2214-2090 / 2000 \mathrm{~g})$ from waste papers and wheat brans supplemented with cotton seed wastes of substrates.

But not in line to the results reported by [28] the maximum $1^{\text {st }}$ flush ranges from $300 \mathrm{~g} / 100 \mathrm{~g}$ to $190 \mathrm{~g} / 100 \mathrm{~g}$ in first harvesting flushes from cotton, coffee pulp and teff straws. The reason for the separation of these results may be the cause of environmental control problems and substrate composition problems. The overall steps in the mushroom production in this experiment are shown by Figure 1.

Table 5. Effects of different mixing amount of wheat straws and waste paper supplemented with cotton seed waste on yield parameters of oyster mushroom.

\begin{tabular}{|c|c|c|c|c|}
\hline \multirow{3}{*}{ Treatments } & \multicolumn{4}{|c|}{ Yield parameters } \\
\hline & \multicolumn{4}{|c|}{ FW } \\
\hline & $1^{\text {st }}$ Flush & $2^{\text {nd }}$ Flush & $3^{\text {rd }}$ Flush & $4^{\text {th }}$ Flush \\
\hline $\mathrm{T} 1$ & $357.0^{c}$ & $178.5^{\mathrm{b}}$ & $184.5^{\mathrm{a}}$ & $153.0^{\mathrm{a}}$ \\
\hline $\mathrm{T} 2$ & $425.0^{\mathrm{b}}$ & $245.5^{\mathrm{a}}$ & $184.0^{\mathrm{a}}$ & $100.0^{\mathrm{c}}$ \\
\hline $\mathrm{T} 3$ & $417.5^{\mathrm{b}}$ & $268.5^{\mathrm{a}}$ & $154.0^{\mathrm{b}}$ & $133.5^{\mathrm{b}}$ \\
\hline $\mathrm{T} 4$ & $444.0^{\mathrm{a}}$ & $265.5^{\mathrm{a}}$ & $167.0^{\mathrm{ab}}$ & $130.5^{\mathrm{b}}$ \\
\hline T5 & $448.5^{\mathrm{a}}$ & $212.5^{\mathrm{b}}$ & $80.5^{c}$ & $71.5^{\mathrm{d}}$ \\
\hline Mean & 418.4 & 234.1 & 154.0 & 117.7 \\
\hline $\mathrm{CV} \%$ & 1.56 & 9.6 & 6.6 & 3.5 \\
\hline $\operatorname{LSD}(5 \%)$ & 18.17 & 62.41 & 28.36 & 11.73 \\
\hline Sign. & $* *$ & ns & $*$ & $*$ \\
\hline
\end{tabular}

Mean values with in a column sharing the same superscript letter(s) are not significantly different by using LSD test at $\mathrm{P} \leq 0.05, \mathrm{FW}=$ fresh weight, $\mathrm{CV}$ $=$ coefficient variances, $\mathrm{LSD}=$ least significant differences at $\mathrm{p}=0.05$
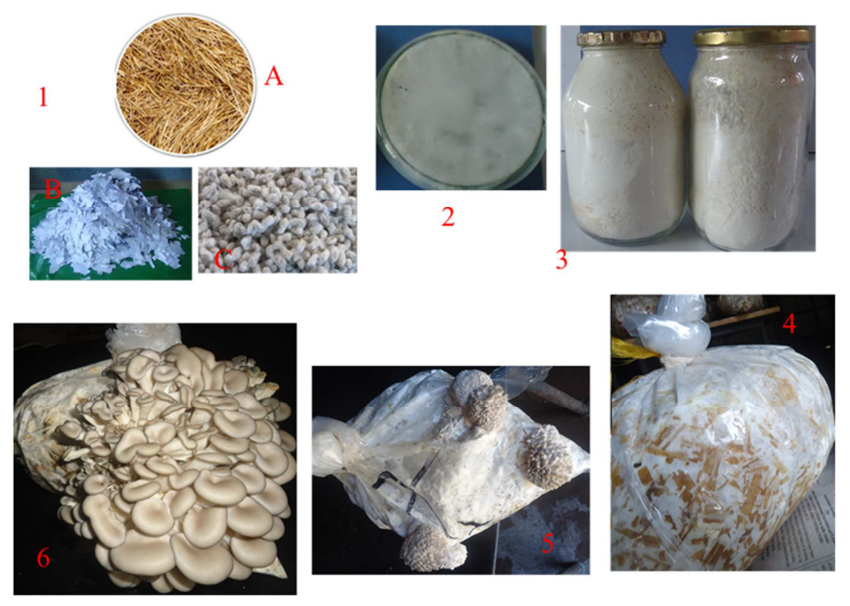

Figure 1. the steps of oyster mushroom production in this experiment: 1) major substrates(A, wheat straw, B, waste paper, $C$, cotton seed waste; 2) pure oyster mushroom culture; 3) oyster mushroom spawn; 4) vegetative growth of mushroom in the production bag;5) propagated primordial on the production bag; 6) oyster mushroom ready for harvest.

\subsection{Total Biomass and Biological Efficiencies of Oyster Mushroom}

The means of biological efficiencies and total biomass of oyster mushroom grown on wheat straws and waste paper supplemented with cotton seed wastes were indicated in (Table 6). The mean biological efficiencies and total biomass of oyster mushroom grown on wheat straws and waste paper supplemented with cotton seed waste showed significant $(\mathrm{p}<$ 0.05) differences within the treatments (Table 6). The maximum mean biological efficiencies and total biomass of 
oyster mushroom produced from those substrates was recorded for T4 (201.35\%; $1006.6 \mathrm{~g}$ respectively), while the lowest biological efficiency and total biomass were recorded for T5 $(162.6 \%, 813 \mathrm{~g}$ respectively). The result of this study were higher as compared to the results reported by [29]on biological efficiencies from $85 \%$ to $71 \%$ on some local available substrates, the reason may be steps of harvesting and nutritional composition of substrates.

But the total biomass were related to the results of [23] $1234 \mathrm{~g}$ to $615.32 \mathrm{~g}$ from wheat straws, rice plus, cotton wastes and waste papers.

Table 6. Effects of different mixing amount of wheat straws and waste paper supplemented with cotton seed waste on yield parameters of oyster mushroom.

\begin{tabular}{lll}
\hline \multirow{2}{*}{ Treatments } & \multicolumn{2}{l}{ yield parameters } \\
\cline { 2 - 3 } & BE & TBM \\
\hline T1 & $185.5^{\mathrm{a}}$ & $873.0^{\mathrm{bc}}$ \\
$\mathrm{T} 2$ & $171.4^{\mathrm{b}}$ & $954.5^{\mathrm{ab}}$ \\
$\mathrm{T} 3$ & $184.5^{\mathrm{a}}$ & $973.5^{\mathrm{a}}$ \\
T4 & $161.3^{\mathrm{c}}$ & $1007.0^{\mathrm{a}}$ \\
T5 & $191.7^{\mathrm{a}}$ & $813.0^{\mathrm{c}}$ \\
Mean & 178.9 & 924.20 \\
MEAN & 1.90 & 3.70 \\
LSD $(5 \%)$ & 9.92 & 94.60 \\
Sign. & $*$ & $*$ \\
\hline
\end{tabular}

Mean values with in a column sharing the same superscript letter(s) are not significantly different by using LSD test at $\mathrm{P} \leq 0.05, \mathrm{TBM}=$ total biomass, $\mathrm{BE}=$ biological efficiencies, $\mathrm{CV}=$ coefficient variances, $\mathrm{LSD}=$ least significant differences.

\section{Conclusions}

Value addition to the agricultural and agro-processing by products through conversion it into the mushroom biomass has been considered as a powerful microbial biotechnology which resulted in the nutritional rich and medicinally useful mushroom biomass, which in turn minimize these solid wastes from the environment and also contribute in the sustainability of the environment. The spent mushroom substrate (left after mushroom biomass harvest) is also very good soil conditioner and use as well for animal feed. The results of this study revealed that mixing of wheat straw, waste paper with the supplement of different proportion of cotton seed waste has been improved yield, yield related parameters and biological efficacy of the oyster mushroom (Pleurotus ostreatus). From all the different treatments tested in this investigation; T4 and $\mathrm{T} 3$ were found to be highest yielding with all the parameters tested, while the rest of the treatments were not gave comparable yields and biological efficiencies; so T3 and T4 of this experiment were need to be evaluated for the small; pilot and commercial scale of oyster mushroom production in the wheat producing agro-climatic zone of the country.

\section{Acknowledgements}

We would like to thank the Ambo University, for materials support and biology laboratory team workers for technical support.

\section{References}

[1] Filippone T. P. (2006). Mushroom history. Accessed on 24/03/2013 from

http://homecooking.about.com/od/foodhistory/a/shroomhistor y.htm

[2] Zeid. D. C, Savoie JM and pardo-Gime nez A (2011). soybean the main nitrogen source in cultivation substrates of Edible and medicinal mushrooms; Soybean and nutrition

[3] Ganopedia (2011). Classification of fungus. Word Press. Accessed on 13/12/2013 from

[4] Chang. S. T (2007). Training manual on mushroom cultivation technology, APCAEM, Accessed on 27/08/2014 from http://www.un-csam.org/publication/TM-Mushroom.pdf

[5] Wasser. S. P. (2002). Medicinal mushrooms as source of antitumor and immunomodulating polysaccharides. Applied Microbiol and Biotechnology, 60. pp258-274.

[6] Hawksworth. D. L (2001). The magnitude of fungal diversity. Mycological Research 105:1422-1432.

[7] Kiflemariam Yehuala (2008). A Paper Presented at the National Mushroom Conference, Addis Ababa University, Ethiopia

[8] Teferi Yenealem, Diriba Muleta and Delelegn Woyessa (2013). Mushroom consumption habits of Wacha Kebele residents, southwestern Ethiopia; Global Research Journal of Agricultural and Biological Sciences, 4 (1). Pp. 6-16.

[9] Dawit A. (1998). Mushroom cultivation: A practical approach. Berhanena Selam Printing Press, Addis Ababa. pp. 16-21.

[10] Boa. E. R.(2004). Wild Edible Fungi: A Global Overview of Their Use and Importance To People. Food Agriculture Organization. Vol 17.

[11] Beetz. A and Kustudia. M (2004). Mushroom cultivation andmarketing: Horticulture production guide. National center forappropriate technology. California. USA

[12] Firenzuoli F, Gori L, Lombardo G (2008). The Medicinal Mushroom Agaricus blazei Murrill: Review of Literature and Pharmaco-Toxicological Problems. CAM.5. 3-15.

[13] Mamiro and Royse (2008). The influence of spawn type and strain on yield, size and mushroom solids contents of Agaricus bisporus produced on non-composited and spent mushroom compost. Bioresource Technology. 99 (8) 3205-3212.

[14] Smiderle, F. R., Olsen, L. M., Ruthes, A. C., Czelusniak, P. A., Santana-Filho, A. P., Sassaki, G. L., and Iacomini, M. (2012). Exopolysaccharides, proteins and lipids in Pleurotus pulmonarius submerged culture using different carbon sources. Carbohydrate Polymers, 87 (1), 368-376.

[15] Mukherjee R and Nandi B (2004). Improvement of in vitrodigestibility through biological, treatment of water hyacinthbiomass by two Pleurotus species. International Biodeterioration and Biodegradation, January 2004.53 (1). 712

[16] Sharma. S and Madan. M (1993). Microbial protein from leguminous and non-leguminous substrates. Acta Biotechnologica. Vol. 13.131-139. 
[17] Amsalu T. (2015). CHEMICAL PULPING OF OXYTENANTHERA ABYSSINICA BAMBOO

[18] ECCIDI (2016). Ethiopian Chemical and Construction Input Development Institute

[19] Dawit Abate (2008). Mushroom cultivation in Ethiopia: status and opportunities. Paper presented at Addis Ababa University, 15 May 2008, science Faculty, Addis Ababa

[20] Asefa K. and Geda K. (2014a). Cultivation of oyster mushroom (pleurotusostreatus) on waste paper with supplemented of wheat bran. Global Journal of Research on Medicinal Plants and Indigenous Medicine3 (10), 370

[21] Asefa, K. and Geda K. (2014b). Cultivations of Oyster Mushroom (Pleurotusostreatus) on Substratum Composed of Waste Papers and Cotton Seed Wastes Advanced J. of Agri. Research 2 (008): 114122

[22] Chang, S. T., Buswell, J. A. and Chiu, S. W. (1993). Mushroom biology and mushroom products. In International Conference on Mushroom Biology and Mushroom Products 1993: Chinese University of Hong Kong). Chinese. University Press.

[23] Soniya S., Ram K. P. Y., Chandra P. PokhrelC. P. (2013). Growth and yield of oyster mushroom (Pleurotus ostreatus) on different substrates. Journal on New Biological Reports, 2 (1), 03-08.

[24] Zenebe G., Weldesemayat G., Getachew B. and Solomon Z. (2016). Growth and yield performance of Pleurotusostreatus
(Jacq. Fr.). Kumm (oyster mushroom) on different substrates. School of Forestry, Wondo Genet Coll ege of Forestry and Natural Resource, Hawassa University, P. O. Box 128, Shashemene, Ethiopia

[25] Nasir A. K., Waqar A. A. A, Muzamil J. and Babar K.(2017). Efficiency of oyster mushroom (pleurotus columbinus - spp ) using Date palm leaves with combination of wheat straw and Cotton waste for its yield improvement. Department of Horticulture Sciences, University of Agriculture, Faisalabad, Pakistan 412 (1) 1245-1325

[26] Kang. W. S. (2004). what is oyster mushroom, Mushroom Growers'Handbook 1. Accessed on 08/06/2014 Oyst. Pleu. From Mushroom. Cultivation/mushroom-growers-handbook-1 mushworld-com-chapter-3pp 1245-1528

[27] Kimenju J. W., Odero O. M., Mutitu E. W., Wachra P. M., Narla R. D., Muiru W. M.(2009). Suitability of locally available substrates for oyster mushroom. (Pleurotus ostreatus) cultivation in Kenya. Asian J. Plant Sci., 8:510 514.

[28] Tsegaye Z. (2015). Growing of oyster mushrooms using agricultural residues at Ethiopian Biodiversity Institute Addis Ababa, Ethiopia. Acad. J. Microbiol. Res. 3 (1): 014-021.

[29] Zinabu H. M., Ameha K. and V. V. Preetha (2015). cultivation of selected pleurotusspecies using sugarcane bagasse, waste paper and leaves of prosopisjuliflora (sw.) dc. International Journal of Advanced Research (2015), Volume 3, Issue 2, $522-531$. 